Research article

\title{
Systematic review of the use of honey as a wound dressing Owen A Moore ${ }^{1}$, Lesley A Smith ${ }^{1}$, Fiona Campbell ${ }^{2}$, Kate Seers ${ }^{2}$, Henry J McQuay ${ }^{1}$ and R Andrew Moore*1
}

Address: ${ }^{1}$ Pain Research Unit and Nuffield Department of Anaesthetics, University of Oxford, Oxford, Radcliffe Hospital, The Churchill, Headington, Oxford OX 3 7LJ, UK and ${ }^{2}$ RCN Institute, Radcliffe Infirmary, Woodstock Road, Oxford OX2 6HE, UK

E-mail: Owen A Moore - omoore@doctors.org.uk; Lesley A Smith - lesley.smith@pru.ox.ac.uk; Fiona Campbell - flona.campbell@rcn.org.uk; Kate Seers - kate.seers@rcn.org.uk; Henry J McQuay - henry.mcquay@pru.ox.ac.uk; R Andrew Moore* - andrew.moore@pru.ox.ac.uk *Corresponding author

Published: 4 June 2001

BMC Complementary and Alternative Medicine 200I, I:2

Received: 8 March 2001

Accepted: 4 June 2001

This article is available from: http://www.biomedcentral.com/I472-6882/I/2

(c) 200 I Moore et al, licensee BioMed Central Ltd.

\begin{abstract}
Objective: To investigate topical honey in superficial burns and wounds though a systematic review of randomised controlled trials.

Data sources: Cochrane Library, MEDLINE, EMBASE, PubMed, reference lists and databases were used to seek randomised controlled trials. Seven randomised trials involved superficial burns, partial thickness burns, moderate to severe burns that included full thickness injury, and infected postoperative wounds.
\end{abstract}

Review methods: Studies were randomised trials using honey, published papers, with a comparator. Main outcomes were relative benefit and number-needed-to-treat to prevent an outcome relating to wound healing time or infection rate.

Results: One study in infected postoperative wounds compared honey with antiseptics plus systemic antibiotics. The number needed to treat with honey for good wound healing compared with antiseptic was 2.9 (95\% confidence interval I.7 to 9.7). Five studies in patients with partial thickness or superficial burns involved less than $40 \%$ of the body surface. Comparators were polyurethane film, amniotic membrane, potato peel and silver sulphadiazine. The number needed to treat for seven days with honey to produce one patient with a healed burn was 2.6 (2.I to 3.4) compared with any other treatment and 2.7 (2.0 to 4.1$)$ compared with potato and amniotic membrane. For some or all outcomes honey was superior to all these treatments. Time for healing was significantly shorter for honey than all these treatments. The quality of studies was low.

Conclusion: Confidence in a conclusion that honey is a useful treatment for superficial wounds or burns is low. There is biological plausibility.

\section{Introduction}

Superficial burns comprise a spectrum of injury severity depending on the depth of the wound and the proportion of the body affected. A burn may be superficial, involving just the epidermal layer of the skin. Partial thickness burns involve damage to more structures within the skin, and full thickness burns involve all layers of the skin and may involve structures beneath. The extent of the injury is usually expressed in percent of total body surface area (TBSA) which is burnt. 
Burn wounds are most commonly dressed using a combination of paraffin-impregnated gauze (designed to prevent adherence of the dressing to the wound) and an absorbent cotton wool layer $[1,2]$. Silver sulphadiazine (SSD) has also been commonly used in burn wound management since 1968 to try to overcome the problem of wound infection.

There is a dearth of good evidence about topical wound agents from systematic reviews of randomised trials [3]. An exception is the subject of dressings and topical agents for chronic wounds, which has been the subject of systematic evidence collecting [4]. Perhaps because of a perceived confusion about what is best in a difficult area, complementary and alternative therapies are increasingly seen as better than conventional. The lack of evidence about either enhances this.

High osmolarity has been considered a valuable tool in the treatment of infections, because it prevents the growth of bacteria and encourages healing [5]. Use of sugar to enhance wound healing has been reported for several hundred patients [6]. High osmolarity can safely be achieved topically by the use of sugar paste or honey, though honey has additionally been regarded as having specific antibacterial properties. For example, honey diluted seven to fourteen-fold beyond the point where osmolality ceased to be completely inhibitory still prevented growth of Staphylococcus aureus $[7,8,9]$.

We sought to investigate the clinical effects of topical honey in superficial burns and wounds though a systematic review of published randomised controlled trials (RCTs). Our view was that key outcomes would be measures of wound healing time and of infection rates.

\section{Methods}

Full published reports of randomised controlled trials of honey in the treatment of burns or wounds were sought. Different search strategies identified reports in MEDLINE (1966 to January 2000), EMBASE (1980 to January 2000), CINAHL (1982 to 2000), PSYCHLIT (1982 to 2000), PubMed (July 2000), and the Cochrane Library (online July 2000). A broad free text search with no restriction to language was undertaken. Reference lists of retrieved reports and reviews [3,4] were searched for additional trials. The Internet was searched, particularly an electronic wound journal (World Wide Wounds; [http://www.smtl.co.uk/World-Wide-Wounds/] ). The date of the last search was 1 August 2000. Unpublished reports and abstracts were not considered. Authors were not contacted for original data.

Inclusion criteria were RCTs comparing honey with a control group in adults or children with burns or wounds, infected or sterile. For inclusion a study had to have at least 10 individuals per treatment group, and clinical or microbiological outcomes. Studies on animals, or laboratory experiments involving assessment of antimicrobial properties of honey were excluded.

Each report that could possibly be described as an RCT was read independently by three of the authors (LAS, OAM, RAM). Trials meeting inclusion criteria were screened independently (authors were not blinded because they already knew the literature) and scored using a three item, 1-5 score, quality scale [10]. The scale takes into account proper randomisation (two possible points), double-blinding (two possible points), and reporting of withdrawals and dropouts (one possible point). Trials were also scored using a five item, o- 16 score, validity scale [11]. This scale takes into account not only the quality of blinding (trials have to be randomised), but also trial size, the validity or appropriateness of outcomes, baseline characteristics of patient groups to ensure sensitivity of the trial, and the quality of data analysis.

From each trial data were extracted on trial design, details of honey and control interventions, outcome measures, statistical analysis, and geographic location of the trial. The main outcomes sought were wounds healed at seven and 21 days, and the number of wounds initially with bacterial growth rendered sterile by treatment at seven and 21 days. The number of patients randomised, or who had initially infected wounds was used as the basis for analysis of healing and infection resolution respectively.

Studies were regarded as having a positive result according to original authors if honey was statistically better than control on any outcome. Authors of the review had to agree that the result was statistically different and that the outcome was useful. Relative benefit and relative risk estimates were calculated with $95 \%$ confidence intervals (CI) using a fixed effects model [12]. Number-needed-totreat (NNT) or number-needed-to-harm $(\mathrm{NNH})$ with 95\% confidence intervals were calculated by the method of Cook and Sackett [13]. A statistically significant difference from control was assumed when the 95\% confidence interval of the relative benefit did not include 1 . Calculations were performed using Excel v 5.0 on a Power Macintosh G3. Heterogeneity tests were not used as they have previously been shown to be unhelpful [14]. Publication bias was not assessed using funnel plots as these tests have been shown to be unhelpful $[15,16]$.

\section{Results}

We found seven randomised trials $[17,18,19,20,21,22,23]$, six performed in India by the 
same researcher $[18,19,20,21,22,23]$, and one [17] performed in the United Arab Emirates (1supplementary material). Two of the studies involved superficial burns $[19,23]$, three partial thickness burns $[20,21,22]$, one moderate to severe burns that included full thickness injury [18], and one infected postoperative wounds [17]. All the controls were active comparisons, though these included potato peelings [20] and amniotic membrane [21] as well as conventional treatments. The main outcomes were the effects of honey and controls on healing time and infection rate, though antibiotic use and hospital stay were also noted in some studies.

None of the studies was blinded and only one designated a primary outcome [23]. The quality score for each trial was 1 out of a possible range of 1-5, and validity scores ranged between 5 and 10 out of range of $o$ to 16 . Of the seven studies, six were deemed positive by the original authors and by authors of this review. One [18] was negative, where tangential excision was statistically better than honey. Because the quality score was 1 in all trials, sensitivity analysis was not possible. Five studies had a mean OPVS score of 8 or less, and four were positive. Both studies with validity scores above 8 were positive.

The single study in infected postoperative wounds compared honey with antiseptics in addition to systemic an- tibiotics after culture and sensitivity [17]. For all outcomes honey was significantly better, with much shorter times for healing, eradication of infection, use of antibiotics and hospital stay (supplementary material). The proportion of wounds healed without dehiscence or resuturing was $22 / 26(85 \%)$ for honey compared with $12 / 24$ (50\%) with antiseptic. The number needed to treat with honey for good wound healing compared with antiseptic was 2.9 (1.7 to 9.7 ).

The single study of moderate or severe burns [18] compared honey with tangential excision. For all outcomes tangential excision followed by grafting by six days post burn was significantly better than initial honey treatment followed by grafting where necessary. Half of all the patients had full thickness burns, and half of those treated with honey eventually needed skin grafts.

The other five studies $[19,20,21,22,23]$ were conducted in patients with partial thickness or superficial burns involving less than $40 \%$ of the body surface. Comparators were polyurethane film [22], amniotic membrane [21], potato peel [20] and silver sulphadiazine $[19,23]$. For some or all outcomes honey was superior to all these treatments. Time for healing was significantly shorter for honey than all these treatments.

Table I: Major outcomes for wound healing and infection for superficial and partial thickness burns

\begin{tabular}{|c|c|c|c|c|c|}
\hline Outcome & Number of trials & $\begin{array}{l}\text { Outcome achieved } \\
\text { with honey (\%) }\end{array}$ & $\begin{array}{l}\text { Outcome achieved } \\
\text { with control (\%) }\end{array}$ & $\begin{array}{l}\text { Relative benefit }(95 \% \\
\text { Cl) }\end{array}$ & NNT $(95 \% \mathrm{Cl})$ \\
\hline \multirow{2}{*}{$\begin{array}{l}\text { 7-day } \\
\text { wound } \\
\text { healing }\end{array}$} & 4 & $\begin{array}{l}97 / 167 \\
(58 \%)\end{array}$ & $\begin{array}{l}29 / 151 \\
(19 \%)\end{array}$ & $\begin{array}{c}3.0(2.2 \text { to } \\
4.3)\end{array}$ & $\begin{array}{l}2.6(2.1 \\
\text { to } 3.4)\end{array}$ \\
\hline & 2 & $\begin{array}{l}43 / 90 \\
(48 \%)\end{array}$ & $\begin{array}{c}8 / 74 \\
(11 \%)\end{array}$ & $\begin{array}{l}4.1(2.1 \text { to } \\
8.2)\end{array}$ & $\begin{array}{l}2.7(2.0 \\
\text { to } 4.1)\end{array}$ \\
\hline \multirow{2}{*}{$\begin{array}{l}21 \text {-day } \\
\text { wound } \\
\text { healing }\end{array}$} & 4 & $\begin{array}{c}165 / 167 \\
(99 \%)\end{array}$ & $\begin{array}{l}|| 3 /|5| \\
(75 \%)\end{array}$ & $\begin{array}{l}1.3(1.2 \text { to } \\
1.4)\end{array}$ & $\begin{array}{l}4.2(3.3 \\
\text { to } 6.0)\end{array}$ \\
\hline & 2 & $\begin{array}{l}90 / 90 \\
(100 \%)\end{array}$ & $\begin{array}{l}70 / 74 \\
(95 \%)\end{array}$ & $\begin{array}{c}1.05(0.99 \text { to } \\
\text { I.I) }\end{array}$ & $\begin{array}{c}21 \text { (10 to } \\
\text { no } \\
\text { benefit) }\end{array}$ \\
\hline \multirow[t]{2}{*}{ infections } & 4 & $\begin{array}{c}\mathrm{II} 4 / \mathrm{I} 34 \\
(85 \%)\end{array}$ & $\begin{array}{l}37 / 124 \\
(30 \%)\end{array}$ & $\begin{array}{c}2.7(2.0 \text { to } \\
3.5)\end{array}$ & $\begin{array}{l}\text { I. } 8(1.5 \\
\text { to } 2.2)\end{array}$ \\
\hline & 2 & $\begin{array}{l}60 / 68 \\
(88 \%)\end{array}$ & $\begin{array}{l}|8 / 6| \\
(30 \%)\end{array}$ & $\begin{array}{c}2.6(1.8 \text { to } \\
3.7)\end{array}$ & $\begin{array}{l}1.7(1.4 \\
\text { to } 2.3)\end{array}$ \\
\hline
\end{tabular}


Percent healed with honey

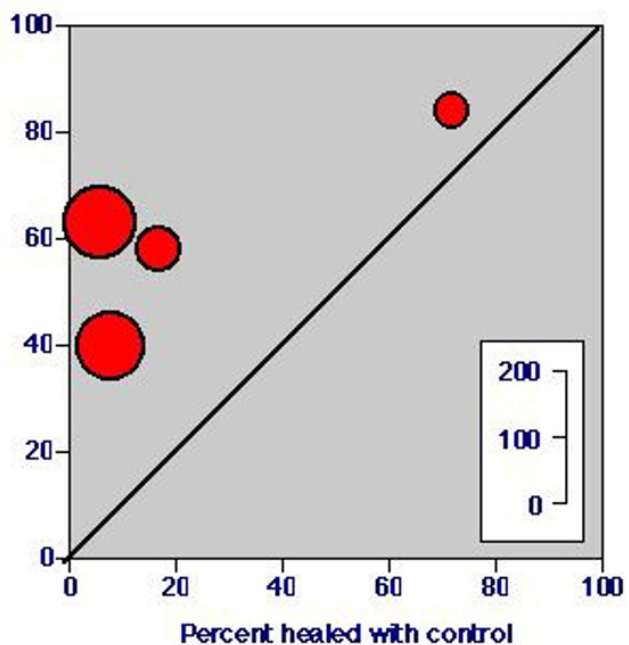

Figure I

Percent of patients healed with honey and other treatments after seven days. The size of the symbol is proportional to the size of the study.

Four studies had dichotomous information about the number of patients healed or with wounds initially infected but which became sterile on treatment $[19,20,21,23]$. Information from these studies has been combined for all four comparisons and for those comparisons (potato, amniotic membrane) where there was no biological plausibility for efficacy (Table 1). The study without dichotomous information [22] reported a statistically significant reduced mean healing time of 10.8 days with honey compared with 15.3 days with polyurethane film.

Treatment with honey produced significantly more healing at seven days. At seven days 58\% (97/167) of patients were healed with honey, and 19\% (29/151) with other treatments (Figure 1). The number needed to treat for seven days with honey to produce one patient with a healed burn was 2.6 (2.1 to 3.4) compared with any other treatment and 2.7 (2.0 to 4.1) for potato and amniotic membrane. By 21 days 99\% (165/167) of patients were healed with honey, and $75 \%(113 / 151)$ with other treatments. The number needed to treat for 21 days with honey to produce one patient with a healed burn was 4.2 (3.3 to 6.0) compared with any other treatment.

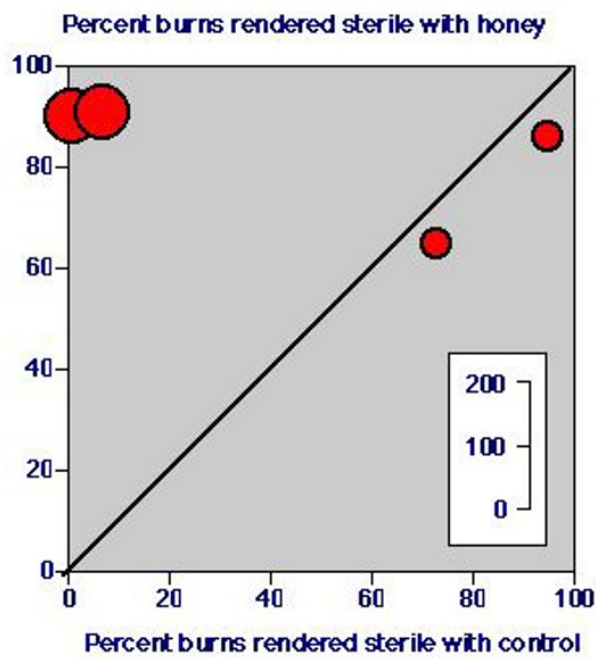

Figure 2

Percent of patients with infected wounds rendered sterile with honey and other treatments after seven days. The size of the symbol is proportional to the size of the study.

At seven days 85\% (114/134) of patients with initially infected wounds had them rendered sterile with honey compared with 30\% (37/124) for other treatments (Figure 2). The number needed to treat for seven days with honey to produce one patient with a sterile wound was 1.8 (1.5 to 2.2 ) compared with any other treatment and 1.7 (1.4 to 2.3) for potato and amniotic membrane. Only one study gave the sterile wound rate at 21 days, $96 \%$ for honey and $76 \%$ for silver sulphadiazine based on limited numbers of patients.

The absence of any adverse effects with honey was positively reported in three studies $[17,20,23]$.

\section{Discussion}

These seven studies give information on 264 patients treated with honey. The studies were of limited quality, and could be influenced by known sources of bias, especially lack of blinding [24], poor reporting quality $[25,26]$, poor validity [11], or size [27]. In addition, six of the studies were conducted by the same researcher. This must mean that the conclusions of the review should be treated with caution. Despite this, six of seven studies comparing honey to other treatments, both conventional and unconventional, showed it to be superior for wound healing, maintenance of sterility or eradication of infec- 
tion. The degree of agreement is considerable (Figures 1 and 2), and the magnitude of the effect impressive (Table 1). The natural resolution of wounds was such that at 21 days the healing rates were high both for honey and comparator treatments. It was the seven day results that were consistently better with honey, using two or four studies, and for wound healing and resolution of infection. The numbers needed to treat were of the order of 2 to 3 , and the effect was comparable with that found for wound healing without dehiscence or resuturing in infected postoperative wounds [17].

There is a biological plausibility, because inhibition of bacterial growth has been shown using impregnated honey discs [9] or incorporating honey into agar plates [7]. How much of this inhibition is due to inherent antimicrobial properties $[7,8,9]$ or to its hyperosmolar nature is unknown. We do know that hyperosmolar sugar paste is effective in experimental animals, and superior to antiseptics [5].

Sugar paste was reported as being used successfully in 605 patients with wounds, burns and ulcers, with lower requirements for skin grafting, antibiotics, and lower hospital costs [6]. What is lacking a way of defining whether the use of honey or sugar paste has any relevance to modern wound management. The problem is a lack of high quality comparative evidence for both conventional and unconventional treatments.

It is difficult to see how the $21^{\text {st }}$ century can be upon us without such evidence being available. The nature of the evidence we have now is such that caution needs still to be exercised. But this review should be of help in designing new, large, randomised studies, with blinded assessment of useful clinical outcomes and compared with standard wound treatments for burns, postoperative wounds and for venous ulcers.

Those studies will not be easy. With honey, we also need to be aware that it is a natural product, and that those characteristics associated with wound healing may be affected by species of bee, geographical location and botanical origin, as well as processing and storage conditions. Some basic knowledge of the importance of these issues is necessary before trials could begin. While these trials would be relevant to industrialised countries to compare honey with conventional treatments, it would be important to conduct them in the less developed world where cost and availability are the key issues.

\section{Additional material}

[http://www.biomedcentral.com/content/supplementary/1472$6882-1-2-s 1 . x \mid s]$

\section{Acknowledgements}

The study was supported with Pain Research funds.

\section{References}

I. Lawrence CJ: A Century after Gamgee. Burns 1987, I 3:77-79

2. Queen D, Evans JH, Gaylor JDS, Courtney JM, Reid WH: Burn wound dressings - a review. Burns 1987, I3:218-228

3. Campbell F, Seers K: Dressing and topical agents for burns (Protocol for a Cochrane Review). In: The Cochrane Library, Issue 3, 2000. Oxford: Update Software.

4. Bradley M, Cullum N, Nelson EA, Petticrew M, Sheldon T, Torgerson D: Systematic reviews of wound care management: (2) Dressings and topical agents used in the healing of chronic wounds. Health Technol Assessment 1999, 3(I 7 Pt2):

5. Archer HG, Barnett S, Irving S, Middleton KR, Seal DV: A controlled model of moist wound healing: comparison between semipermeable film, antiseptics and sugar paste. J Exp Pathol 1990, 7 I: $155-70$

6. Knutson RA, Merbitz LA, Creekmore MA, Snipes HG: Use of sugar and povidone-iodine to enhance wound healing: five year's experience. South Med J 1981, 74:1329-35

7. Cooper RA, Molan PC, Harding KG: Antibacterial activity of honey against strains of Staphylococcus aureus from infected wounds. J Roy Soc Med 1999, 92:283-5

8. Cooper R, Molan P: The use of honey as an antiseptic in managing Pseudomonas infection. J Wound Care 1999, 8:161-4

9. Karayil S, Deshpande SD, Koppikar GV: Effect of honey on multidrug resistant organisms and its synergistic action with three common antibiotics. J Postgrad Med 1998, 44:93-6

10. Jadad AR, Moore RA, Carroll D, Jenkinson C, Reynolds DJM, Gavaghan $D J$, McQuay $H$ J: Assessing the quality of reports of randomized clinical trials: is blinding necessary? Control Clin Trial 1996, 17:1-12

II. Smith LA, Oldman AD, McQuay HJ, Moore RA: Teasing apart quality and validity in systematic reviews: an example from acupuncture trials in chronic neck and back pain. Pain 2000, 86: I 19- 132

12. Morris JA, Altman DG: Calculating confidence intervals for relative risk, odds ratios and standardised ratios and rates. Statistics with confidence -confidence intervals and statistical guidelines. Edited by Gardner MJ, Altman DG. London: BMJ 199550-63

13. Cook RJ, Sackett DL: The number needed to treat: a clinically useful measure of treatment effect. BM] 1995, 3 I 0:452-4

14. Gavaghan DJ, Moore RA, McQuay HJ: An evaluation of homogeneity tests in meta-analyses in pain using simulations of individual patient data. Pain 2000, 85:4I5-424

15. J Tang, JL Liu: Misleading funnel plot for detection of bias in meta-analysis. J Clin Epidemiol 2000, 53:477-484

16. Sterne JA, Gavaghan D, Egger M: Publication and related bias in meta-analysis. Power of statistical tests and prevalence in the literature . J Clin Epidemiol 2000, 53: I I I9-29

17. Al-Waili NS, Saloom KY: Effects of topical honey on post-operative wound infections due to Gram positive and Gram negative bacteria following Caesarean sections and hysterectomies. Eur / Med Res 1999, 4:126-30

18. Subrahmanyam M: Early tangential excision and skin grafting of moderate burns is superior to honey dressing: a prospective randomised trial. Burns 1999, 25:729-31

19. Subrahmanyam M: A prospective randomised clinical and histological study of superficial burn wound healing with honey and silver sulfadiazine. Burns |998, 24:|57-6I

20. Subrahmanyam M: Honey dressing versus boiled potato peel in the treatment of burns: a prospective randomized study. Burns 1996, 22:491-3

21. Subrahmanyam M: Honey-impregnated gauze versus amniotic membrane in the treatment of burns. Burns 1994, 20:331-3

22. Subrahmanyam $M$ : Honey impregnated gauze versus polyurethane film (OpSite) in the treatment of burns - a prospective randomised study. Br J Plastic Surg 1993, 46:322-3

23. Subrahmanyam M: Topical application of honey in treatment of burns. Br J Surg 1991, 78:497-8

24. Schulz KF, Chalmers I, Hayes RJ, Altman DG: Empirical evidence of bias: Dimensions of methodological quality associated with estimates of treatment effects in controlled trials. JAMA 1995, 273:408-12 
25. Khan KS, Daya S, Jadad AR: The importance of quality of primary studies in producing unbiased systematic reviews. Arch Intern Med 1996, 156:66I-6

26. Moher D, Pham B, Jones A, et al: Does quality of reports of randomised trials affect estimates of intervention efficacy reported in meta-analyses? Lancet 1998, 352:609-613

27. Moore RA, Gavaghan D, Tramèr MR, Collins SL, McQuay HJ: Size is everything - large amounts of information are needed to overcome random effects in estimating direction and magnitude of treatment effects. Pain 1998, 78:217-220

\section{Pre-publication history}

The pre-publication history for this paper can be accessed here:

http://www.biomedcentral.com/content/backmatter/I472-

6882-I-2-bl.pdf

Publish with BioMedcentral and every scientist can read your work free of charge

"BioMedcentral will be the most significant development for disseminating the results of biomedical research in our lifetime."

Paul Nurse, Director-General, Imperial Cancer Research Fund

Publish with BMc and your research papers will be:

- available free of charge to the entire biomedical community

- peer reviewed and published immediately upon acceptance

- cited in PubMed and archived on PubMed Central

- yours - you keep the copyright

Submit your manuscript here:

http://www.biomedcentral.com/manuscript/

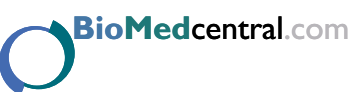

editorial@biomedcentral.com 